\title{
Analisis Daerah Dugaan Seismic Gap di Sulawesi Utara dan sekitarnya
}

\author{
Sandy Nur Eko Wibowoa,b*, As'aria, Slamet Suyitno Raharjob \\ aJurusan Fisika, FMIPA, Unsrat, Manado \\ bBadan Meteorologi Klimatologi dan Geofisika
}

\begin{tabular}{l}
\hline K A T A K U N C I \\
\hline Seismic gap \\
nilai-b \\
Mekanisme fokus \\
Periode ulang
\end{tabular}

\begin{tabular}{l}
\hline K E Y W O R D S \\
\hline Seismic gap \\
b-value \\
focal mechanism \\
Recurrence period
\end{tabular}

AVAILABLE ONLINE 25 Februari 2014

A B S T R A K
Seismic gap adalah kawasan yang aktif secara tektonik namun
sangat jarang mengalami gempabumi dalam jangka waktu yang lama.
Terdapat dua daerah dugaan seismic gap yang terdapat di daerah
Sulawesi Utara antara lain daerah Laut Maluku dan Laut Sulawesi. Pada
penelitian ini akan dianalisis sejauh mana potensi bahaya dua daerah
dugaan seismic gap tersebut didasarkan pada profil perubahan parameter
seismotektonik nilai $b$, analisis mekanisme fokus, perubahan nilai rasio
$v_{p} / V_{s}$, periode ulang gempabumi dan prediksi parameter patahan di dua
daerah penelitian. Diperoleh bahwa hanya daerah dugaan seismic gap di
Laut Maluku yang dapat dikategorikan sebagai daerah seismic gap yang
berpotensi menimbulkan gempabumi dengan energi besar dan tsunami
sebagai efek terusan gempabumi.
A B S T R A C T
Seismic gap is a tectonically active region, but very rarely experienced
earthquakes in the long term. There are two alleged seismic gap area of
the North Sulawesi region, that are Maluku Sea and the Sulawesi Sea
areas. This research analyzed potential danger of the two alleged seismic
gap area in North Sulawesi based on $b$ value seismotectonic profile
parameter changes, the analysis of the focal mechanism, changes in the
value of the ratio $v_{p} / v_{s}$, earthquake recurrence period, and fault
parameters prediction at the two areas. It was found that the alleged area
of Maluku Sea could be categorized as a seismic gap area with a
potentially earthquake and tsunami energy which was the after effects of
the earthquake.

di zona subduksi Alaska-Aleutian (Nishenko dan Sykes, 1993).

Seismic gap yang merupakan daerah yang berpotensi mengalami gempabumi dengan energi yang besar tidak hanya terdapat di Sumatera, tetapi tersebar di hampir seluruh kawasan Indonesia. Kertapati, 2006, menjelaskan keberadaan daerah seismic gap pada beberapa daerah subduksi di Indonesia dengan tingkat prioritas potensi gempabumi yang berbeda. Natawidjaja, 2007, juga menjelaskan bahwa di Indonesia terdapat 9 kawasan yang diduga sebagai daerah seismic gap, diantaranya kawasan Simeleu, Mentawai, Selat

\footnotetext{
*Corresponding author: Jurusan Fisika FMIPA UNSRAT, Jl. Kampus Unsrat, Manado, Indonesia 95115; Email address: sandy_geof41@yahoo.com Published by FMIPA UNSRAT (2014)
} 
Sunda, Selatan Jawa, Utara Papua, Utara Halmahera dan wilayah Laut Maluku yang berbatasan langsung dengan Sulawesi Utara.

Daerah dugaan seismic gap yang terdapat di Laut Maluku, merupakan daerah yang diwaspadai, karena selain berpotensi mengalami gempabumi dengan energi besar, posisinya yang terletak di laut akan menimbulkan potensi tsunami sebagai efek terusan gempabumi.

Berdasarkan hal ini, maka telah dilakukan penelitian guna memetakan lokasi dan menganalisis bahaya seismic gap di Laut Maluku dan Laut Sulawesi.

Penelitian ini bertujuan untuk membandingkan dua daerah dugaan seismic gap di sekitar Laut Maluku dan Laut Sulawesi, memetakan potensi gempabumi dalam skala besar yang mungkin terjadi di daerah dugaan seismic gap, dan menghitung parameter gempabumi maksimum yang berpeluang terjadi pada daerah dugaan seismic gap.

Manfaat dari penelitian ini adalah sebagai masukan informasi dalam upaya mitigasi bencana gempabumi dan tsunami di daerah Sulawesi Utara dan sekitarnya

\section{Metode}

Data yang digunakan dalam penelitian ini mencakup data episenter gempabumi katalog International Seismological Center (ISC) periode 1900 - 2012 dengan batasan wilayah 10LS - 30LU dan $120^{\circ}$ - $130^{\circ} \mathrm{BT}$ dan kedalaman gempa 1 $80 \mathrm{Km}$, data mekanisme patahan gempabumi katalog Global Centroid Moment Tensor (CMT) periode tahun 1976-2012, Raw Data Seiscomp3 BMKG Stasiun Geofisika Manado periode tahun 2007 - 2012. Diagram alir penelitian ditunjukkan pada Gambar 1.

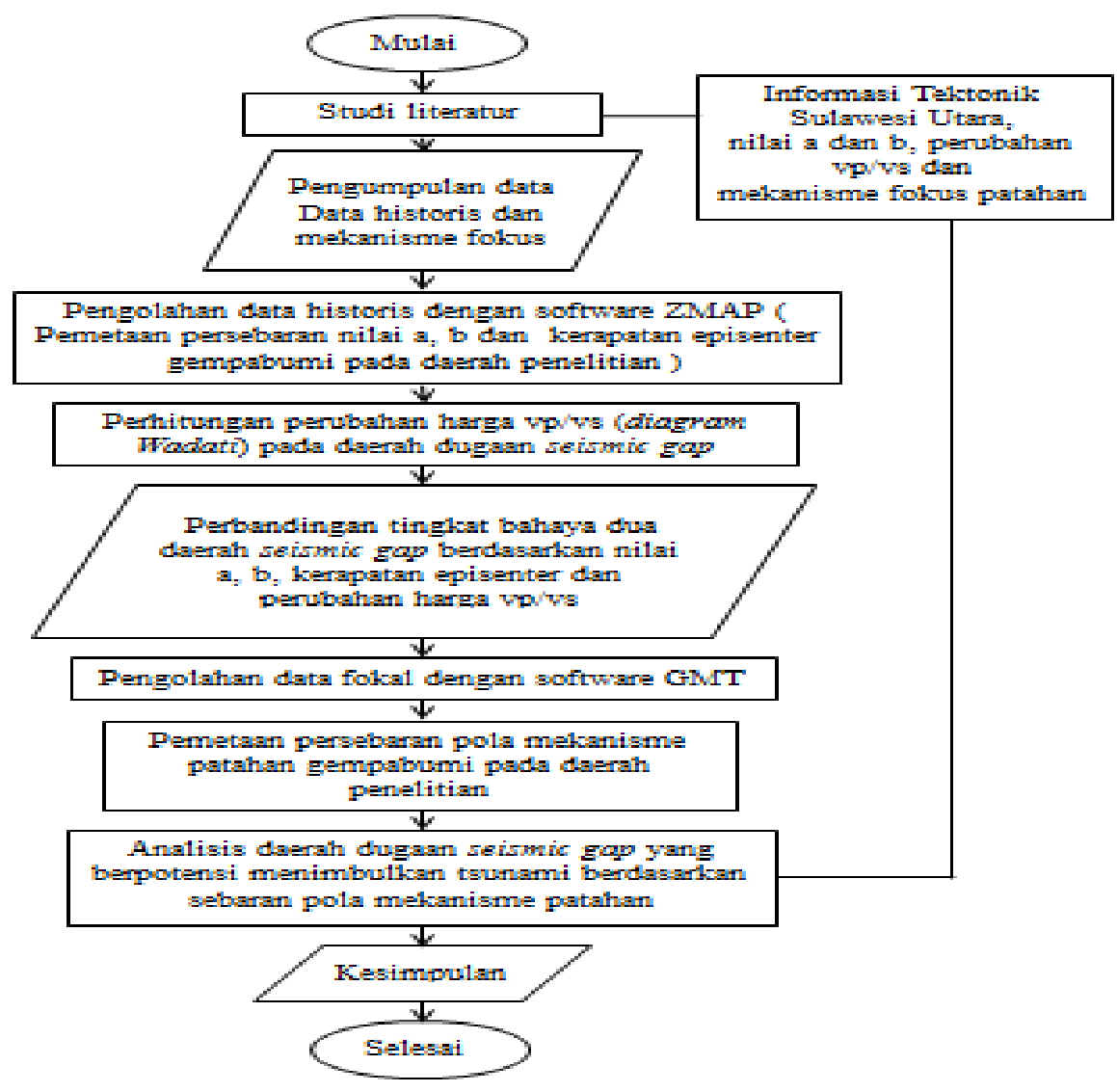

Gambar 1. Diagram alir penelitian.

3. Hasil dan Pembahasan

\subsection{Pemetaan distribusi} seismotektonik $a$ dan $b$

\section{a. Distribusi Frekuensi - Magnitudo}

Dengan menggunakan software analisis ZMAP dapat diperoleh kurva distribusi frekuensi magnitude gempabumi di daerah dugaan seismic gap Laut Maluku dan Laut Sulawesi. Kedua kurva ini ditunjukkan pada Gambar 2 dan 3.
Dari kurva distribusi frekuensi - magnitudo, didapatkan nilai Mc (Magnitude Completeness) yaitu 4,9 untuk daerah Laut Maluku dan 5,2 untuk daerah Laut Sulawesi 


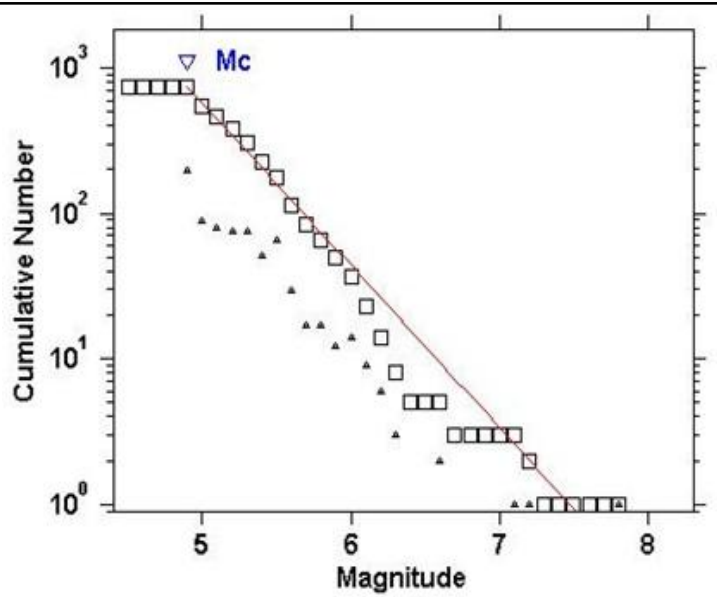

Maximum Likelihood Solution

b-value $=1.12+1-0.04$, a value $=8.34$

Magnitude of Completeness $=4.9$

Gambar 2. Kurva Distribusi Frekuensi - Magnitudo daerah dugaan seismic gap di Laut Maluku

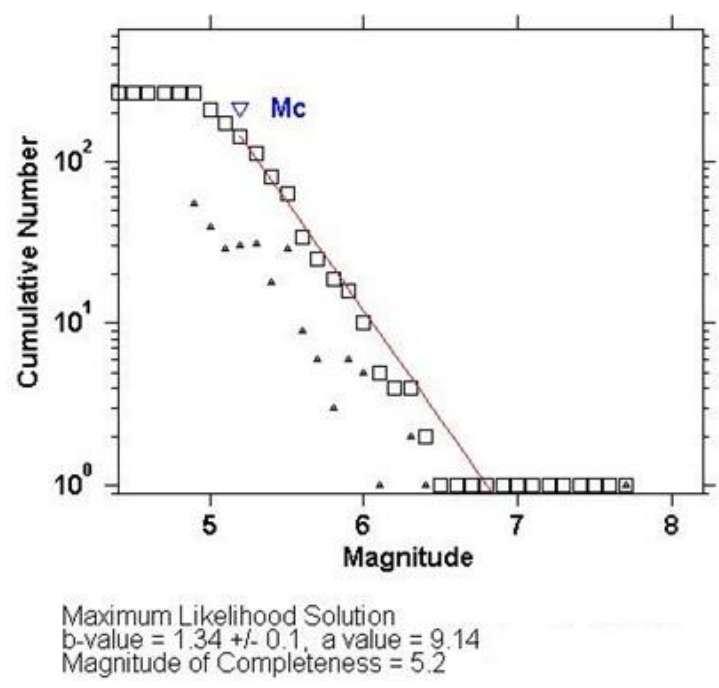

Gambar 3. Kurva Distribusi Frekuensi - Magnitudo daerah dugaan seismic gap di Laut Sulawesi

\section{a. Pemetaan nilai $a$ dan $b$}

Setelah Kurva Distribusi Frekuensi Magnitudo didapatkan, nilai Mc (Magnitude Completeness) akan diperoleh sehingga nilai a dan b dapat dipetakan melalui Metode Maksimum Likelyhood menggunakan software analisis ZMAP (Wiemer \& Wyss, 2002). Pemetaan nilai $a$ dan $b$ ditunjukkan pada Gambar 4 dan 5.

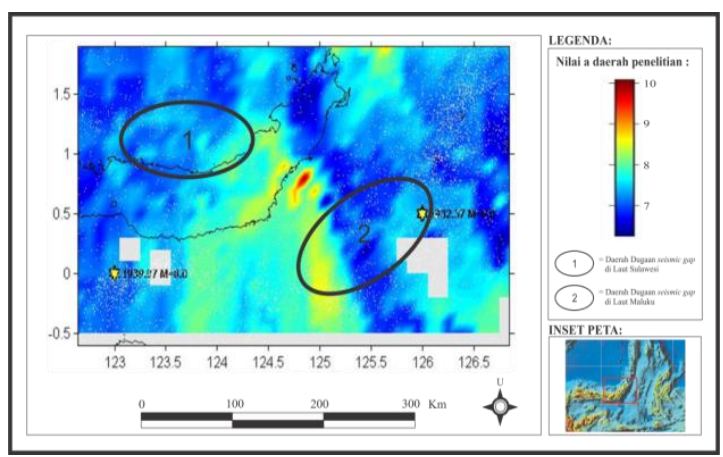

Gambar 4. Pemetaan nilai a daerah penelitian

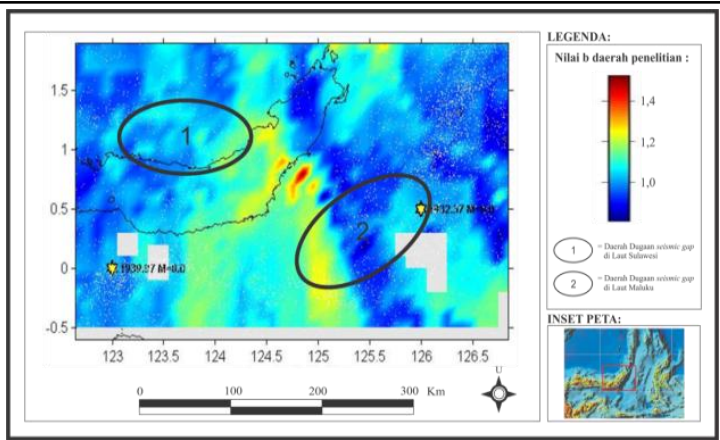

Gambar 5. Pemetaan nilai $b$ daerah penelitian

Pada Gambar 4 dan 5 terlihat bahwa daerah dugaan seismic gap di Laut Sulawesi memiliki nilai a dan $b$ yang relatif lebih besar dibandingkan dengan daerah dugaan seismic gap di Laut Maluku. Selanjutnya dibuat profil perubahan nilai $b$ terhadap waktu untuk daerah dugaan seismic gap di Laut Maluku dan Sulawesi (Gambar 6 dan 7).

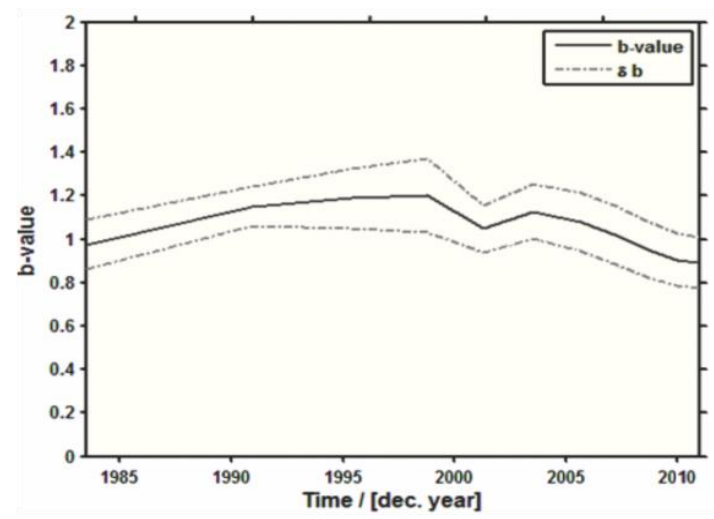

Gambar 6. Grafik perubahan nilai b terhadap waktu di daerah dugaan seismic gap di Laut Maluku

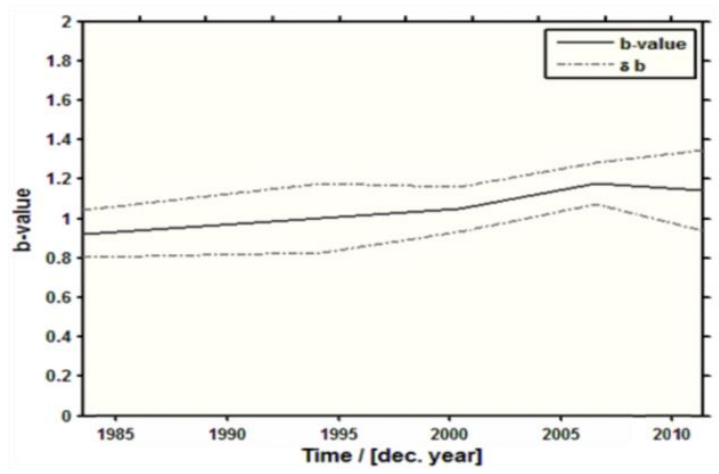

Gambar 7. Grafik perubahan nilai b terhadap waktu di daerah dugaan seismic gap di Laut Sulawesi

\subsection{Periode Ulang Gempabumi di daerah dugaan seismic gap}

Dari nilai a dan b yang didapatkan (Gambar 2 dan 3) dapat ditentukan periode ulang gempabumi skala 7 di daerah penelitian. Pemetaan periode ulang gempabumi di kedua daerah penelitian ditunjukkan pada Gambar 8 dan 9. 


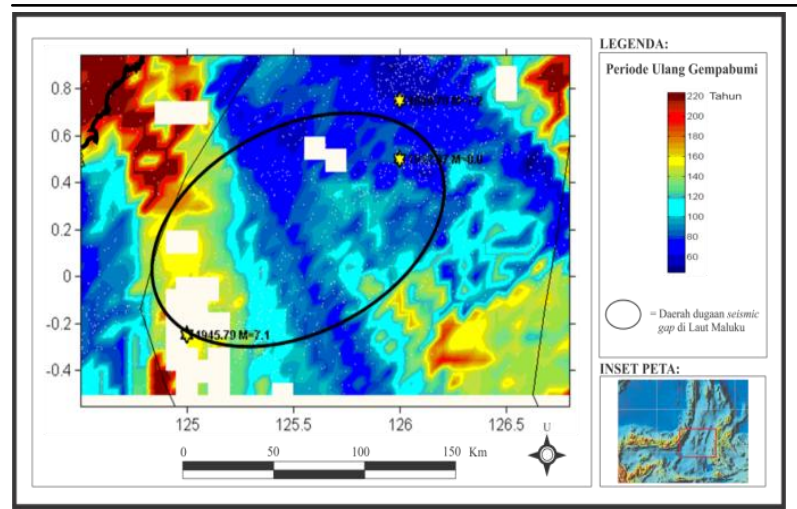

Gambar 8. Pemetaan Periode Ulang Gempabumi skala 7 di Laut Maluku

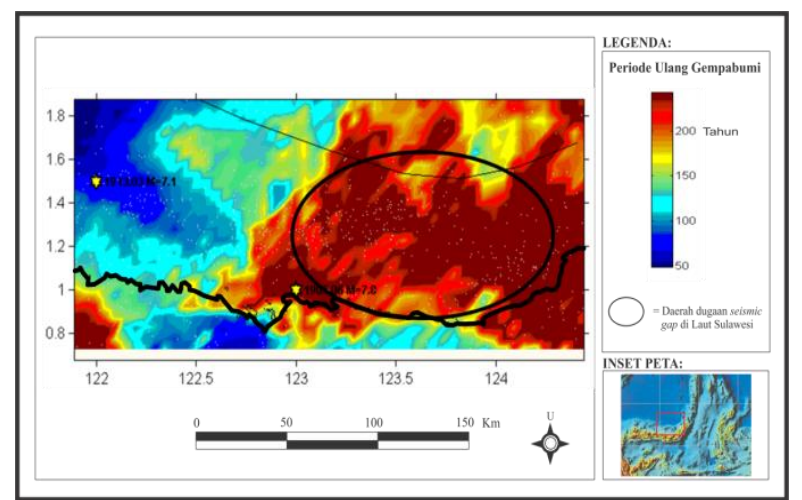

Gambar 9. Pemetaan Periode Ulang Gempabumi skala 7 di Laut Sulawesi

Dari Gambar 8 dan 9 di atas, terlihat periode ulang gempabumi skala 7 di kedua daerah penelitian. Daerah dugaan seismic gap di Laut Maluku memliki tingkat periode ulang gempabumi skala 7 sekitar 70 - 140 tahun dan daerah dugaan seismic gap di Laut Sulawesi memiliki tingkat periode ulang sekitar 200 - 250 tahun.

\subsection{Perhitungan Perubahan nilai $v_{p} / v_{s}$}

Dari data mentah waktu tiba gelombang $p$, gelombang $s$ dan waktu kejadian gempabumi yang didapatkan dari software Seiscomp3 di BMKG Stasiun Geofisika Manado periode tahun 2007 2012 dapat ditentukan variasi nilai $v_{p} / v_{s}$ di kedua daerah penelitian.

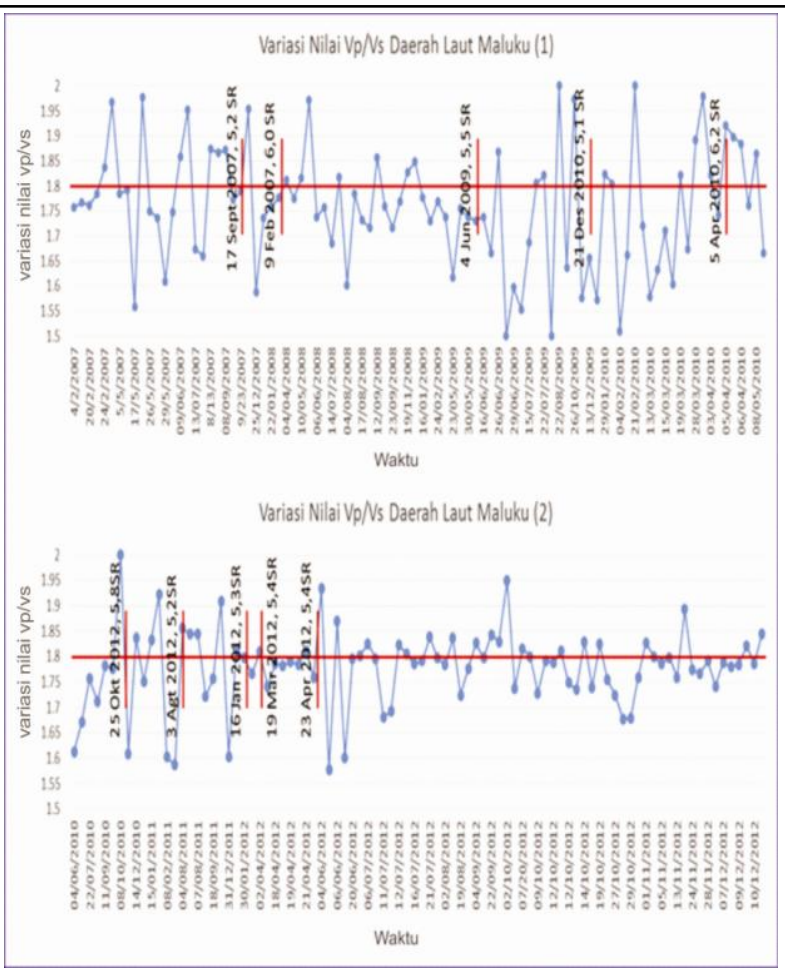

Gambar 10. Variasi nilai $v_{p} / v_{s}$ di daerah dugaan seismic gap di Laut Maluku

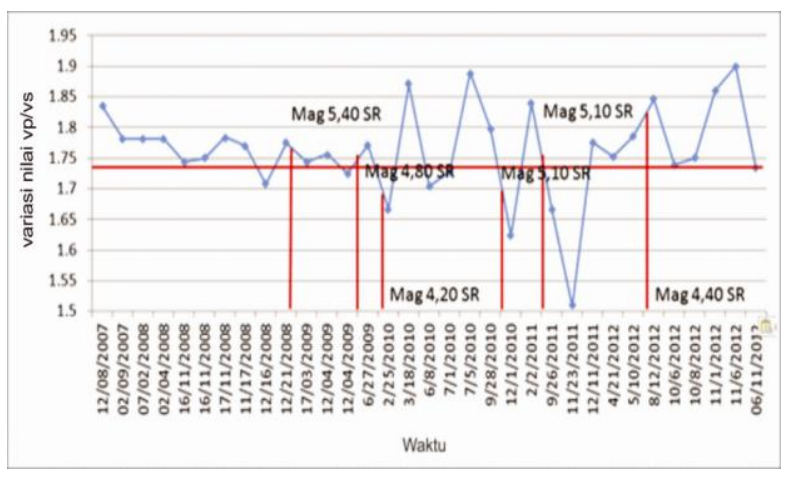

Gambar 11. Variasi nilai $v_{p} / v_{s}$ di daerah dugaan seismic gap di Laut Maluku

\subsection{Analisis tingkat bahaya daerah penelitian}

Dari berbagai unsur yang diteliti terlihat bahwa daerah dugaan seismic gap di Laut Maluku memiliki karakteristik yang lebih mendekati daerah seismic gap, antara lain Nilai $b$ yang cenderung menurun hingga akhir periode pengamatan dan variasi perubahan nilai $v_{p} / v_{s}$ yang signifikan sebelum terjadinya gempabumi yang mengindikasikan terjadinya akumulasi energi.

\subsection{Sebaran pola mekanisme patahan daerah dugaan seismic gap di Laut Maluku}

Dari data mekanisme patahan yang berasal dari katalog Global CMT, dapat dipetakan sebaran pola mekanisme patahan di daerah dugaan seismic gap di Laut Maluku (Gambar 12). 


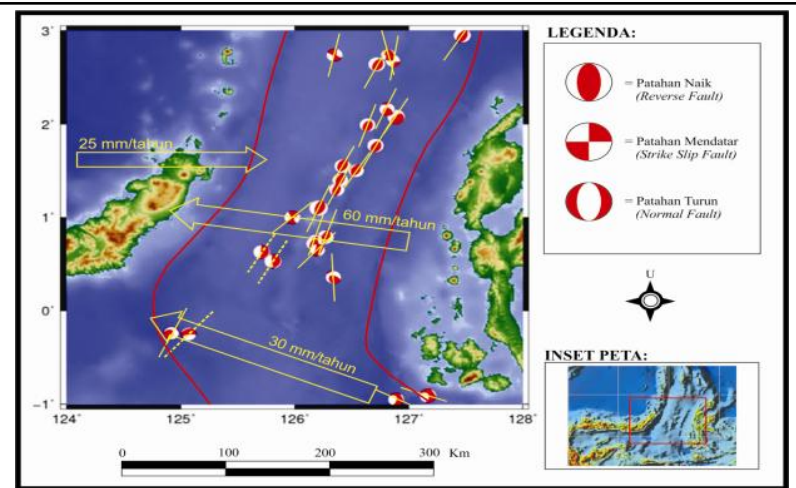

Gambar 12. Sebaran pola mekanisme patahan di daerah dugaan seismic gap di Laut Maluku

\subsection{Prediksi pola mekanisme patahan daerah dugaan seismic gap di Laut Maluku}

Prediksi sudut dan panjang patahan daerah dugaan seismic gap di Laut Maluku ditunjukkan pada Gambar 13.

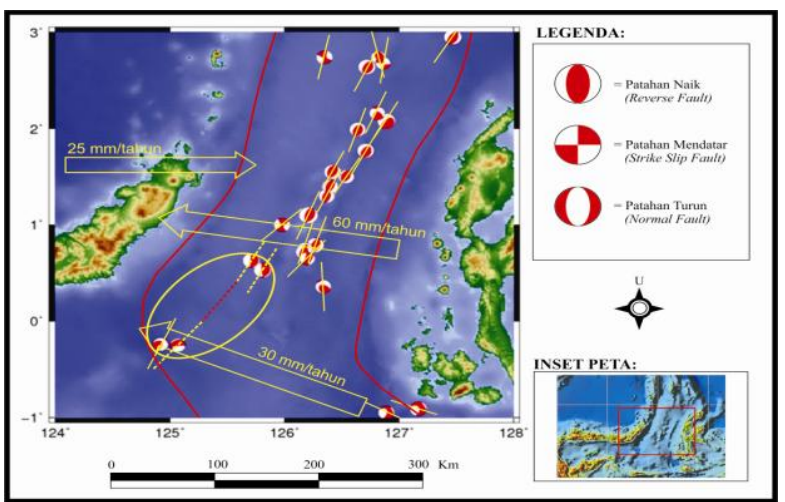

Gambar 13. Prediksi sudut dan panjang patahan daerah dugaan seismic gap di Laut Maluku

\section{Kesimpulan}

Dari penelitian ini dapat disimpulkan beberapa hal berikut:

1. Daerah dugaan seismic gap di Laut Maluku memiliki karakteristik yang lebih mendekati karakteristik daerah seismic gap dibandingkan daerah dugaan seismic gap di Laut Sulawesi.

2. Gempabumi berskala besar berpotensi terjadi di daerah dugaan seismic gap di Laut Maluku.

3. Daerah dugaan seismic gap di Laut Maluku berpotensi mengalami gempabumi pemicu tsunami dengan prediksi parameter panjang patahan $142 \mathrm{~km}$, lebar patahan $58,2 \mathrm{~km}$, deformasi permukaan dasar laut $6,01 \mathrm{~m}$ dan magnitudo 8,3.

\section{Daftar Pustaka}

[1] Global Centroid Moment Tensor. Global CMT Catalogue. Global CMT Bulletin. http://www. globalcmt.org/CMT search.html [15 April 2013].

[2] International Seismological Center. Event Catalogue. ISC Bulletin. http://www.isc.ac.uk/ iscbulletin/search/catalogue. [24 Desember 2012].

[3] Kertapati, E. 2006. Aktivitas Gempabumi di Indonesia, Persfektif Regional pada Karakteristik Gempabumi Merusak. Badan Geologi. Bandung.

[4] Nishenko, S. P., dan Sykes, L. R. 1993. Comment on Seismic gap hypothesis: Ten years after by Y. Y. Kagan and D. D. Jackson. 98: 9909-9916. J. Geophys. Res.

[5] Wiemer, S. dan Wyss, M. 2002. ZMAP : A Cookbook. ETII. Zurich. 